\title{
Nanocrystalline-modified nickel ferrite films: an effective sensor for industrial and environmental gas pollutant detection
}

\author{
Prashant Bhimrao Koli ${ }^{1}$ D $\cdot$ Kailas Haribhau Kapadnis ${ }^{2} \cdot$ Uday Gangadhar Deshpande $^{1}$
}

Received: 26 January 2019 / Accepted: 29 March 2019 / Published online: 5 April 2019

(c) The Author(s) 2019

\begin{abstract}
The inverse spinel nanocrystalline pure and doped nickel ferrite particles were synthesized by co-precipitation method. The thick films of both pure and doped nickel ferrite nanoparticles were prepared by coating the material on glass substrate via screen printing method. The XRD was used to confirm cubic, crystalline nickel ferrites. The scanning electron microscopy confirms nanosized, cubic nanoparticles of nickel ferrite, and their morphology was investigated. The energy-dispersive spectroscopy was used to comprise elemental composition for pure and doped ferrites. Transmission electron microscopy was attributed for investigation of surface morphology, crystal structure identification of nickel ferrites. The FT-IR was used to find the vibrational frequencies, symmetric, asymmetric stretching and bending modes of metal oxide linkage. The thick films of nickel ferrite were employed for sensing phenomenon of gases such as LPG, $\mathrm{NO}_{2}, \mathrm{CH}_{3}-\mathrm{OH}, \mathrm{C}_{2} \mathrm{H}_{5}-\mathrm{OH}, \mathrm{NH}_{3}$ and petrol vapours. The pure nickel ferrite showed excellent results for ammonia and nitrogen dioxide gases up to 90.42 and 86.42 , respectively. Manganese- and cobalt-doped ferrites were excellent for ammonia and petrol vapours. Modified nickel ferrite effect of dopants cobalt and manganese was investigated. Pure and doped ferrites showed excellent response and recovery for ammonia, $\mathrm{NO}_{2}$, petrol vapours and $\mathrm{LPG}$ gases.
\end{abstract}

Prashant Bhimrao Koli

prashantkoli005@gmail.com

1 Research Centre in Chemistry and PG Department of chemistry, Pratap College of Arts, Science and Commerce, Amalner, Affiliated to KBC-NMU, Jalgaon 425401, Maharashtra, India

2 Research Centre in Chemistry and PG Department of chemistry, Loknete Vyankatrao Hiray Arts, Science and Commerce College, Affiliated to SPPU, Panchavati, Nashik, Pune 422003, Maharashtra, India 


\section{Graphical abstract}

The graphical abstract presenting the synthesis process of pure and modified nickel ferrite prepared by co-precipitation method. The prepared material ferrite thick films were exclusively utilized for the detection of some pollutant gases.

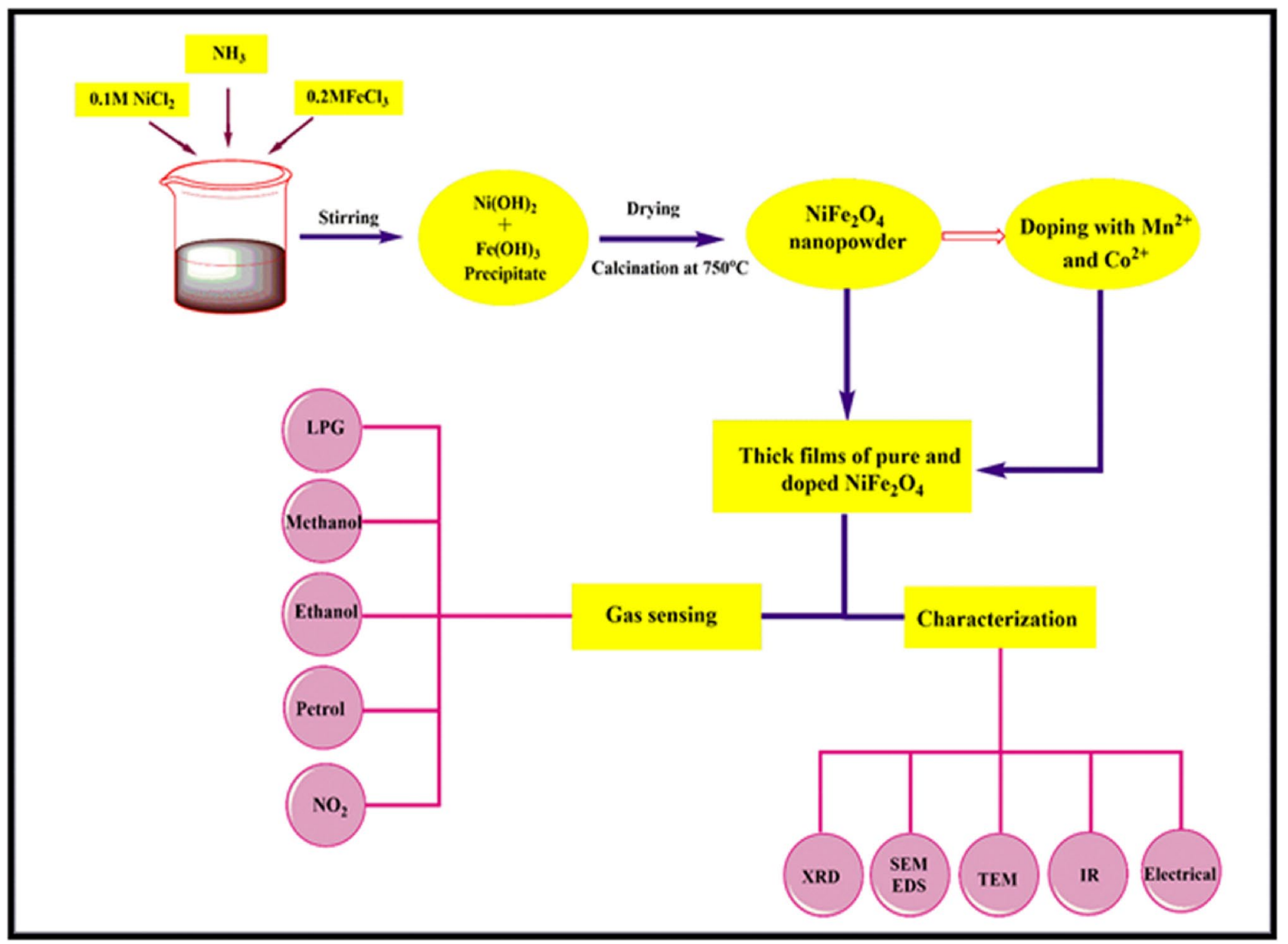

Keywords Gas pollutants $\cdot \mathrm{NiFe}_{2} \mathrm{O}_{4}$ thick films $\cdot$ Gas sensing $\cdot \mathrm{SEM} \cdot \mathrm{TEM} \cdot \mathrm{EDS}$

\section{Introduction}

Material science becomes a promising field of nanoscience, due its remarkable applications in the research. It covers wide range of research applications such as sensors [1-3], adsorption, photocatalysis, biosensors, solar cells, conducting material, drug distribution, photovoltaic, medicinal, agricultural and catalytical applications, sultriness sensors [4-10].Nowadays, enormous incrimination in the level of pollution and industrial hazards is the major threat for environment. The evolution of toxic substances and gases from industries as well as from conveyances are the major sources of pollutant gases. These toxic gases which are inimical for environment must be detected so that the hazards due to gas leakage and gas emission can be detected very expeditiously. Most commonly, gas sensors are facile material for the detection of minuscule concentration of gases at sundry places [11]. Commonly, semiconducting metal oxides including $\mathrm{ZnO}, \mathrm{NiO}, \mathrm{TiO}_{2}$, $\mathrm{SnO}_{2}, \mathrm{CuO}, \mathrm{Nb}_{2} \mathrm{O}_{5}, \mathrm{ZrO}_{2}, \mathrm{Fe}_{2} \mathrm{O}_{3}, \mathrm{Co}_{3} \mathrm{O}_{4}$, etc. are extensively utilized by researchers for catalytical applications, whereas class of $M \mathrm{Fe}_{2} \mathrm{O}_{4}(M=\mathrm{Ni}, \mathrm{Co}, \mathrm{Zn}, \mathrm{Mn}$, etc.), sundry perovskite materials, such as $\mathrm{LaFeO}_{3}, \mathrm{LaCrO}_{3}$ as well as some spinel such as $\mathrm{Mn}_{3} \mathrm{O}_{4}$ and inverse spinel compounds, have been fabricated for sensing purport [12-14]. These types of oxides can be utilized for the detection of sundry inimical gases. All the nanosensors are highly accessible, thermally stable for sundry gases. In particular, nickel ferrite is an excellent material for sensing the gases such as LPG, $\mathrm{H}_{2} \mathrm{~S}$, methane, $\mathrm{Cl}_{2}$ and $\mathrm{NH}_{3}$ [15]. 
The ferrite members are intensively studied material for sundry applications and show sundry types of magnetic properties which include ferromagnetism, ferrimagnetism, antiferromagnetism which are utilized in many electronic contrivances [16]. According to researchers, the ferrimagnetic comportment of the nickel ferrite is due to magnetic moments with spin-paired arrangement that arises spin orientation between $\mathrm{Fe}^{3+}$ ions located in tetrahedral voids and $\mathrm{Ni}^{2+}$, $\mathrm{Fe}^{2+}$ located at octahedral voids. Categorically, nickel ferrite is a magnetic material with n-type semi-conduction possessing the efficacious band gap $2.5 \mathrm{eV}$ by which this material can be employed for many catalytical applications [17, 18]. Nickel ferrite possesses plenarily inverse spinel structure with $\lambda=1$, where $\lambda$ corresponds to degree of inversion and can be defined as number of tetrahedral sites occupied by $\mathrm{M}^{3+}$ ions. The $M \mathrm{Fe}_{2} \mathrm{O}_{4}$ are spinel solid materials in which $M$ is divalent cation. The inverse spinel can be identified from the distribution of divalent ions that occupied tetrahedral voids and some of the trivalent ions additionally occupy tetrahedral voids in integration to octahedral voids. The distribution is attributed to gain more crystal field stabilization energy in the case of inverse spinels. The stretching and bending modes of nickel ferrite individual ions distributed in octahedral and tetrahedral voids can be assigned from IR data, which gives the characteristics bands for each distribution. However, in the case of mundane spinels structure the divalent stringently occupies tetrahedral voids and fine-tuned trivalent ions occupy octahedral voids; transmutations in this distribution result in the formation of inverse spinel material [19-21]. There are several methods utilized for the synthesis of nickel ferrites such as co-precipitation method, hydrothermal synthesis, sol-gel method, combustion method, sonochemical synthesis, plasma deposition method, electrospinning, high-energy milling, spray pyrolysis method, magnetic sputtering, water CTAB method, micro-emulsion method, electrochemical method, precursor method, etc. [22-24]. According to the literature, the pristine phase material, i.e. without doping may show less sensitivity for several gases, but in several reports the nickel ferrite doped by d-block elements was found to be a very efficient catalyst for sensing mechanism. In particular, minute concentration of nickel and cobalt can enhance the electrical, optical, mechanical and sensing properties of this material. The Pt-doped nickel ferrite showed high sensitivity towards several reductant gases such as $\mathrm{NH}_{3}$ and $\mathrm{H}_{2} \mathrm{~S}$. In several cases, coinage metal (Pt, $\mathrm{Pd}$, $\mathrm{Ag}, \mathrm{Au}$ )-doped ferrites showed excellent sensitivity for liquefied petroleum gas and petrol vapours. Researchers now coalesce to develop the sultriness sensors and sensors which can work at room temperature; this type of research activity is in great demand right now. Sultriness sensors can be utilized for household and industrial hazards due to gas leakage everywhere. Nanocrystalline nickel ferrite can provide efficacious grain size which provides sizably voluminous surface area to promote the adsorption of sundry gases $[25,26]$. In the present research, we investigated the structural and electrical properties as well as gas sensing performance for pure $\mathrm{NiFe}_{2} \mathrm{O}_{4}$ and $\mathrm{Co}^{2+}, \mathrm{Mn}^{2+}$ doped $\mathrm{NiFe}_{2} \mathrm{O}_{4}$ nanocrystalline thick films prepared by conventional screen printing method as the metal oxide semiconducting materials are very prominent for sundry applications and being utilized by researchers for sensing mechanism. We prepared sensors of pristine and doped nickel ferrites, and its sensitivity was investigated for LPG, $\mathrm{NO}_{2}$, $\mathrm{CH}_{3}-\mathrm{OH}, \mathrm{C}_{2} \mathrm{H}_{5}-\mathrm{OH}, \mathrm{NH}_{3}$ and petrol vapours. The research article includes synthesis of nickel ferrite and effect of dopant nickel and cobalt concentration on functional material nickel ferrite. All the data of gas sensing obtained from pristine and doped ferrites were interpreted and compared to draw conclusions about difference of pure and doped ferrites for the detection of culled gases. All parameters examined for pristine and doped nickel ferrite are discussed in detail in results and discussions section.

\section{Materials and methods}

All the chemicals used in the synthesis are of AR grade purchased from Modern Laboratories, Nashik, and were used without further purification. Chemicals required for the synthesis of nickel ferrite are ferric chloride, nickel chloride, cobalt chloride, manganese chloride, ammonia, doubledistilled water.

\section{Synthesis of nickel ferrite by co-precipitation method}

The nickel ferrite nanoparticles were prepared in 1:2 mol ratio of nickel chloride and iron chloride, respectively, in $20 \mathrm{ml}$ of double-distilled dihydrogen monoxide, commixed exhaustively at room temperature. The solution was then commixed in $200 \mathrm{ml}$ ammonia solution with constant stirring. The $\mathrm{pH}$ of the solution was adjusted up to 12 by the addition of concentrated ammonium hydroxide solution. The resulting nanoparticles were dissevered by centrifugation at $3000 \mathrm{rpm}$ for $10 \mathrm{~min}$. The product was washed with doubledistilled dihydrogen monoxide and then by ethanol. The precursor of nickel and iron hydroxide was then kept in oven at $70{ }^{\circ} \mathrm{C}$ for $30 \mathrm{~min}$. Conclusively, the precursor was transferred to silica crucible and kept in furnace at $750{ }^{\circ} \mathrm{C}$ for calcination up to $6 \mathrm{~h}$, and the fine powder brown-coloured nickel ferrite nanoparticles were obtained [27].

\section{Preparation of $\mathrm{Mn}^{2+}$ and $\mathrm{Co}^{2+}$ doped nickel ferrite by physical doping method}

Five per cent (atomic weight \%) dopant concentration of cobalt chloride and manganese chloride $(0.05 \mathrm{~g}$ each) was added to $0.6 \mathrm{~g}$ of pure nickel ferrite. The inorganic and organic ratios were kept constant as 70:30, respectively. 
The inorganic part consists of the doped nickel ferrite nanoparticles, whereas the organic part considers the $8 \%$ butyl carbitol acetate (BCA) and 92\% ethyl cellulose (EC). All these compounds were added in mortar and pestle previously washed by acetone and dried. BCA was added drop wise to the above mixtures to achieve the proper pseudoplastic phase (thixotropic), to get a viscous paste. The paste was then applied on previously cut glass substrate $(2 \times 1 \mathrm{~cm})$, by screen printing method. The standard mask size was developed on the screen by photolithography technique, the films were air-dried for $15 \mathrm{~min}$, and then, the films were dried under IR lamp for $30 \mathrm{~min}$. Finally, the films were calcined under muffle furnace at $750{ }^{\circ} \mathrm{C}$ for $4 \mathrm{~h}$. The doped nickel ferrites thick films are ready for characterization and further use [28].

\section{Synthesis of thick film sensor of pure and doped $\mathrm{NiFe}_{2} \mathrm{O}_{4}$ by conventional screen printing method}

The thick films of pure and $\mathrm{Mn}^{2+}, \mathrm{Co}^{2+}$ doped $\mathrm{NiFe}_{2} \mathrm{O}_{4}$ were yare by screen printing technique, in which the inorganic and organic ratios were kept constant as 70:30, respectively. The inorganic part consists of the pure nickel ferrite nanoparticles and doped nickel ferrite nanoparticles, whereas organic part considers the $8 \%$ butyl carbitol acetate (BCA) and $92 \%$ ethyl cellulose. All these compounds were integrated in mortar and pestle which was washed by acetone and dried. BCA was added drop by drop slowly to the above amalgamations to achieve the congruous pseudoplastic phase (thixotropic), to get a viscous paste. The paste was then applied on previously cut glass substrate $(2 \times 1 \mathrm{~cm})$, by screen printing method. The screen of nylon (40 s, mesh number 355) was utilized for screen printing. The standard mask size was developed on the screen by photolithography technique, the films were dried at room temperature for $15 \mathrm{~min}$, and then, the films dried under IR lamp for $30 \mathrm{~min}$. Then, these films were calcined under muffle furnace at $750{ }^{\circ} \mathrm{C}$ for $4 \mathrm{~h}$. The pure and doped nickel ferrites thick films are yare for characterization and further use.

\section{Thickness measurement of the films}

The thickness of the films was measured by scanning the thick film in UV-visible spectrophotometer model number Jassco-UV 730 in the range of $300-800 \mathrm{~nm}$. The thickness of the films for pure nickel ferrite was observed to be 9.607 $\mu \mathrm{m}(9607 \mathrm{~nm})$, while for the doped ferrite the thickness of the glass coated film was found to be $4.101 \mu \mathrm{m}(4101 \mathrm{~nm})$.

\section{Characterization techniques}

The typical XRD pattern of the thick films of pure and doped nickel ferrite was recorded by using D8 advance Bruker

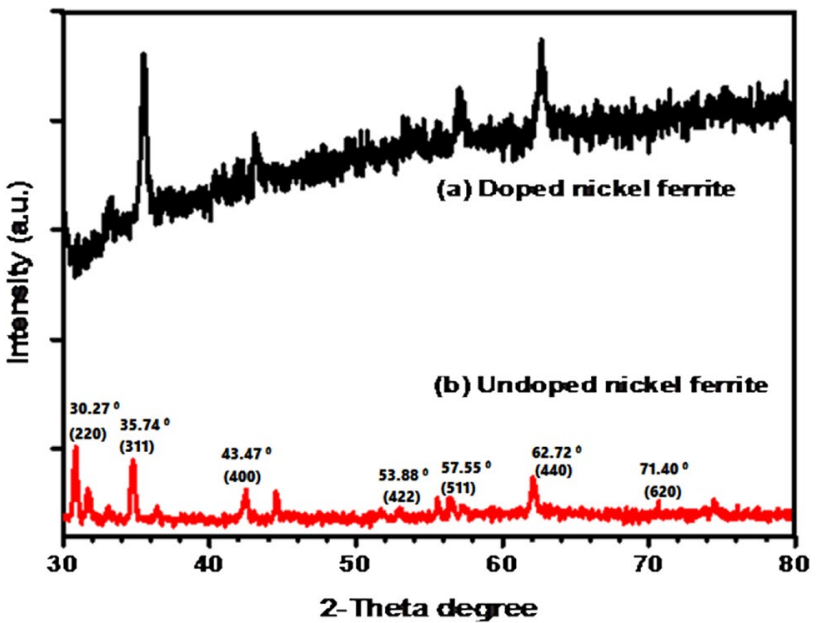

Fig. 1 a XRD spectrum of $\mathrm{Co}^{2+}$ and $\mathrm{Mn}^{2+}$ doped nickel ferrite. b $\mathrm{XRD}$ spectrum of undoped nickel ferrite

AXS GmbH (Germany), Bragg's scanning angle varying from $10^{\circ}$ to $80^{\circ}$. The surface morphology and characteristics of the material were analysed by using scanning electron microscope (SEM), model number S 4800 Type II High Technologies Corporation, Japan. The elemental composition and atomic weight percentage of all the elements in the pure and doped nickel ferrite films were investigated by using energy-dispersive X-ray spectroscopy (EDAX), model number X Flash detector 5030 make Bruker AXS GmbH, Germany. Transmission electron microscope (TEM) was utilized to find out crystallinity, morphological features and crystal type of pure and doped ferrites; model used for TEM analysis was CM200 make Philips with operating voltage $20-200 \mathrm{kV}$, resolution $2.4 \AA$ which can produce magnification up to $1,000,000 \times$. The sample of TEM was analysed with the help of copper grid. Both the pure and doped nickel ferrite films were analysed by Fourier-transform infrared spectroscopy (FT-IR) to find out different stretching and bending vibrations of $\mathrm{Fe}-\mathrm{O}, \mathrm{Ni}-\mathrm{O}, \mathrm{Co}-\mathrm{O}, \mathrm{Mn}-\mathrm{O}$ oxide linkages in inverse spinel environment. FT-IR analysis was performed by using Spectrum RX-IFTIR, PerkinElmer with resolution of $1 \mathrm{~cm}^{-1}$ and scanning range of $4000-250 \mathrm{~cm}^{-1}$.

\section{Results and discussion}

\section{X-ray diffraction (XRD)}

The pure and doped $\mathrm{NiFe}_{2} \mathrm{O}_{4}$ thick films calcined at $750{ }^{\circ} \mathrm{C}$ were characterized by XRD, with model number $\mathrm{D} 8$ advance Bruker AXS GmbH (Germany). The films were analysed at room temperature with $\mathrm{MoK} \alpha$ radiations (wavelength 1.54 $\AA$ ). The XRD spectrum (Fig. 1) clearly indicates the formation of crystalline nickel iron oxide as per data obtained. 
Bragg's reflection peaks are attributed to the formation of $\mathrm{NiFe}_{2} \mathrm{O}_{4}$ material with FCC crystal lattice and $\mathrm{Fd} 3 \mathrm{~m}$ space group. The match scan data of $\mathrm{NiFe}_{2} \mathrm{O}_{4}$ show the formation of crystalline $\mathrm{NiFe}_{2} \mathrm{O}_{4}$ nanoparticles with JCPDS number 00-003-0875. Diffraction peaks obtained are 30.273, 35.744, $43.473,53.888,57.559,62.728,71.403$ that are assigned to the reflection of (220), (311), (400), (422), (511), (440), (620) planes [29].The lattice constant $(a=b=c)$ for nickel ferrite was found to be $A=8.3400$, which is found to be in the range of standard lattice constant value $A=8.33$ [30]. No additional peaks of any compound or impurity were observed in XRD spectrum indicating that the prepared nickel ferrite is pure. All the above-cited diffraction patterns confirm the formation of nickel ferrite $\left(\mathrm{NiFe}_{2} \mathrm{O}_{4}\right)$ nanoparticles. The average particle size was calculated by using Debye-Scherer's formula: $[D=K \lambda / \beta \cos \theta]$, where $D$ is average particle size, $K$ is constant $(0.9-1), \beta$ is full width half maxima (FWHM) of diffracted peak, $\theta$ is the angle of diffraction. The average particle size for pure nickel ferrite was found to be $23 \mathrm{~nm}$, and for doped nickel ferrite it is found to be $40 \mathrm{~nm}[31,32]$.

\section{Field emission gun scanning electron microscopy: (FEG-SEM)}

The surface morphology of prepared ferrite nano-powder was analysed by SEM (model number S 4800 Type II High Technologies Corporation, Japan) Fig. 2 illustrating the SEM micrographs of prepared pure $\mathrm{NiFe}_{2} \mathrm{O}_{4}$ and $\mathrm{Mn}^{2+}$, $\mathrm{Co}^{2+}$ doped $\mathrm{NiFe}_{2} \mathrm{O}_{4}$ nanoparticles showing the spherical sphere-shaped nanoparticles agglomerated together to give better surface area to prepared material, calcined at $750{ }^{\circ} \mathrm{C}$. Figure 2a, b shows that the different-sized nanoparticles $(\sim 1 \mu \mathrm{m})$ with regular porous material are very useful for the sensing mechanism, as the porous material provides ease to adsorb the gas vapours yielding more response for gaseous molecule on the surface via chemisorption and physisorption. The small voids can also be found in SEM images of pure and doped ferrites which can act as adsorbent for various gaseous moieties [33, 34].

The agglomerated nanocrystalline ferrite nanoparticles are seen in Fig. 2b; the doping elements $\mathrm{Mn}$ and Co in minute concentrations are found to be agglomerated in doped ferrites forming smaller lumps of various nanosized nanoparticles, while in undoped ferrite the small-sized nanoparticles are highly agglomerated to form a homogeneous lattice that is seen in Fig. 2a. The SEM results can be comparable with XRD data of pure and doped ferrites where the sharp peaks in XRD data indicate highly crystalline nickel ferrite nanoparticle formation [35]. The specific surface area of pure $\mathrm{NiFe}_{2} \mathrm{O}_{4}$ and modified $\mathrm{NiFe}_{2} \mathrm{O}_{4}$ nanoparticles was calculated using BET method for spherical particles using
Eq. (1). The data obtained from BET are represented in Table 1.

$\mathrm{Sw}=6 / \rho \times d$,

where Sw is the surface area, 6 (six) is the constant, $\rho$ is the composite density of the materials, $d$ is the average particle size of functioning material.

\section{Particle size distribution from SEM analysis}

The particle size distribution curve (PSD) obtained from SEM image of pure and modified nickel ferrite is shown in Fig. 2c, d. The PSD gives an idea about the dimensions of solid tiny particles distributed in a material sometime in the colloidal state. Among the popular methods of PSD such as photo-analysis, sedimentation technique and optical counting technique which involves electron micrograph analysis (EMA). Here, EMA was the tool used to investigate the PSD of both ferrite materials. Both distribution curves of maximum particle size were found to be $10-35 \mathrm{~nm}$ which is in good agreement with the results obtained from XRD and SEM [36, 37].

\section{Energy-dispersive X-ray spectroscopy (EDS)}

The energy-dispersive X-ray spectroscopy was acclimated to investigate the elemental composition of prepared pure nickel ferrite and doped nickel ferrite. Figure $3 \mathrm{a}, \mathrm{b}$ shows the EDS pictures for pristine and doped ferrite materials. The sharp peak 6.3, 7.0 keV for iron and 7.5, 8.3 keV in pristine EDS spectrum, while in doped nickel ferrite the iron is observed in the same scale at $6.3,7.0 \mathrm{keV}$, the nickel was found at $7.5,8.3 \mathrm{keV}$. The dopant metal cobalt resolved at $1.7,3.7$ and manganese at $5.8,6.3 \mathrm{keV}$. All the data obtained from EDS attest the formation pristine and doped nickel ferrite nanocrystals as well as were found to be in good acquiescent with the reported data [38].

\section{High-resolution transmission electron microscopy: (HR-TEM)}

The TEM pictures of pure nickel ferrite are shown in Fig. 4a-d for doped nickel ferrite which clearly shows the typical cubic-shaped nanocrystalline phase for both pure and doped ferrites. The particle size observed in TEM images is about $20-50 \mathrm{~nm}$ in pure nickel ferrite while $50-100 \mathrm{~nm}$ for doped nickel ferrite. And also minute concentration of doped material cobalt and manganese cubic-shaped particles are clearly seen in TEM images of doped nickel ferrite. The particle size obtained from TEM is found to be in good agreement with the XRD data [39-41]. 

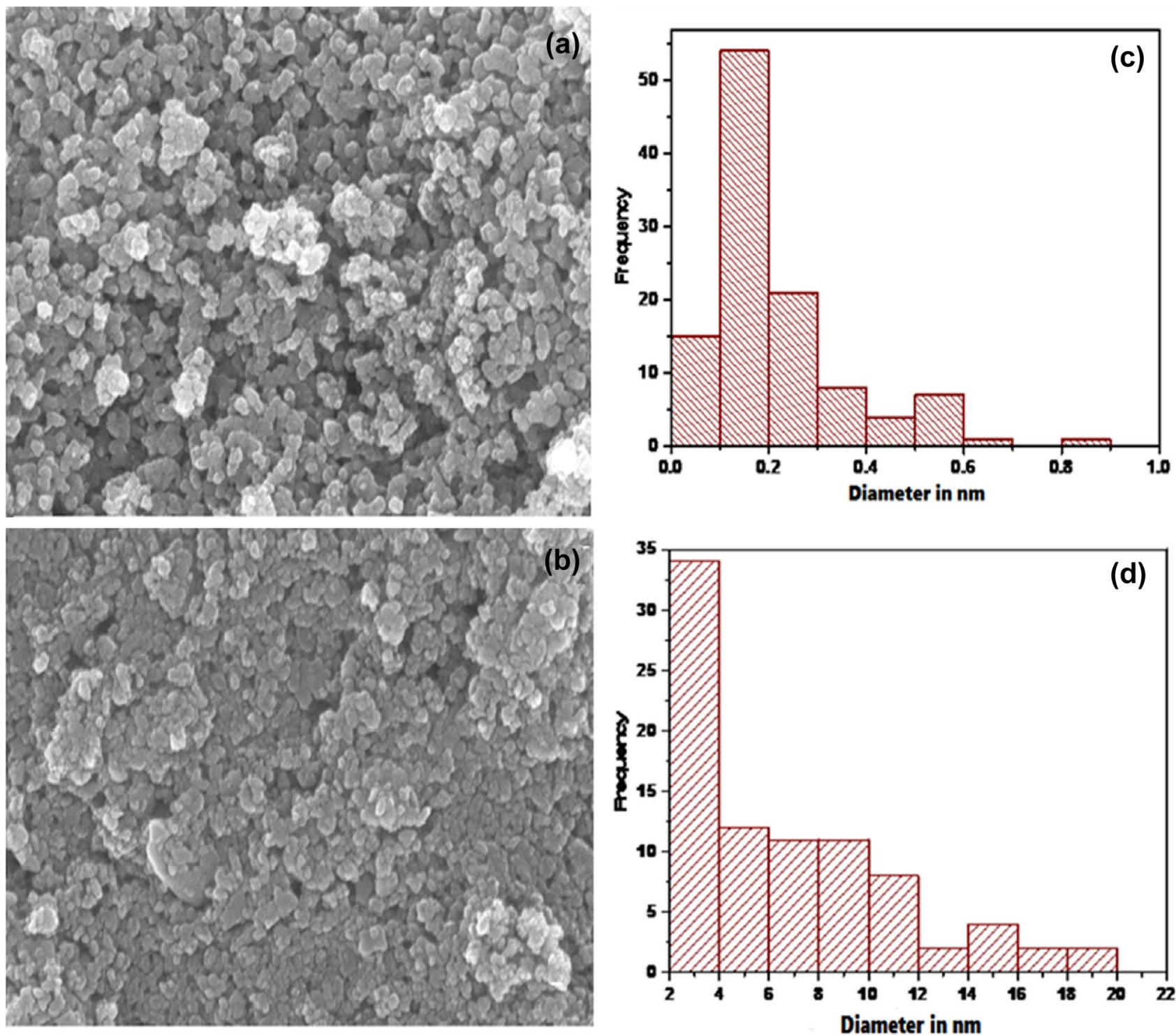

Fig. 2 a SEM image of pure $\mathrm{NiFe}_{2} \mathrm{O}_{4}$. b SEM image of $\mathrm{Mn}^{2+}$ and $\mathrm{Co}^{2+}$ doped $\mathrm{NiFe}_{2} \mathrm{O}_{4}$. c Particle size distribution curve of pure $\mathrm{NiFe}_{2} \mathrm{O}_{4}$. d Particle size distribution curve of doped $\mathrm{NiFe}_{2} \mathrm{O}_{4}$

Table 1 Surface area and particle size calculated using BET method for spherical particles from SEM data

\begin{tabular}{lllll}
\hline Functioning material & $\begin{array}{l}\text { Firing tempera- } \\
\text { ture }\left({ }^{\circ} \mathrm{C}\right)\end{array}$ & $\begin{array}{l}\text { Crystallite (grain) size, } \\
D \text { nm }(\mathrm{XRD})\end{array}$ & $\begin{array}{l}\text { Particle size, } d \\
\mathrm{~nm}(\mathrm{SEM})\end{array}$ & $\begin{array}{l}\text { Specific } \\
\text { surface area } \\
\text { in } \mathrm{m}^{2} / \mathrm{g}\end{array}$ \\
\hline${\text { Pure } \mathrm{NiFe}_{2} \mathrm{O}_{4}}$ & 750 & 23 & 200 & $2.65 \times 10^{2}$ \\
Doped $\mathrm{Nife}_{2} \mathrm{O}_{4}$ & 750 & 40 & 222 & $4.85 \times 10^{2}$ \\
\hline
\end{tabular}

\section{Selected area electron diffraction (SAED) analysis}

The typical SAED pattern of pure and doped nickel ferrite can be seen in (Fig. 5a, b) where a clear diffraction pattern of pure crystalline nickel ferrite nanoparticles and doped nickel ferrite is observed. The pattern can be assigned for the typical $h k l$ values or typical characteristic planes of nickel ferrite. The SAED data obtained are in good agreement with the diffraction data obtained from XRD [42]. 
Fig. 3 a EDAX image and elemental composition of pure $\mathrm{NiFe}_{2} \mathrm{O}_{4}$. b EDAX image and elemental composition of $\mathrm{Mn}^{2+}$ and $\mathrm{Co}^{2+}$ doped $\mathrm{NiFe}_{2} \mathrm{O}_{4}$

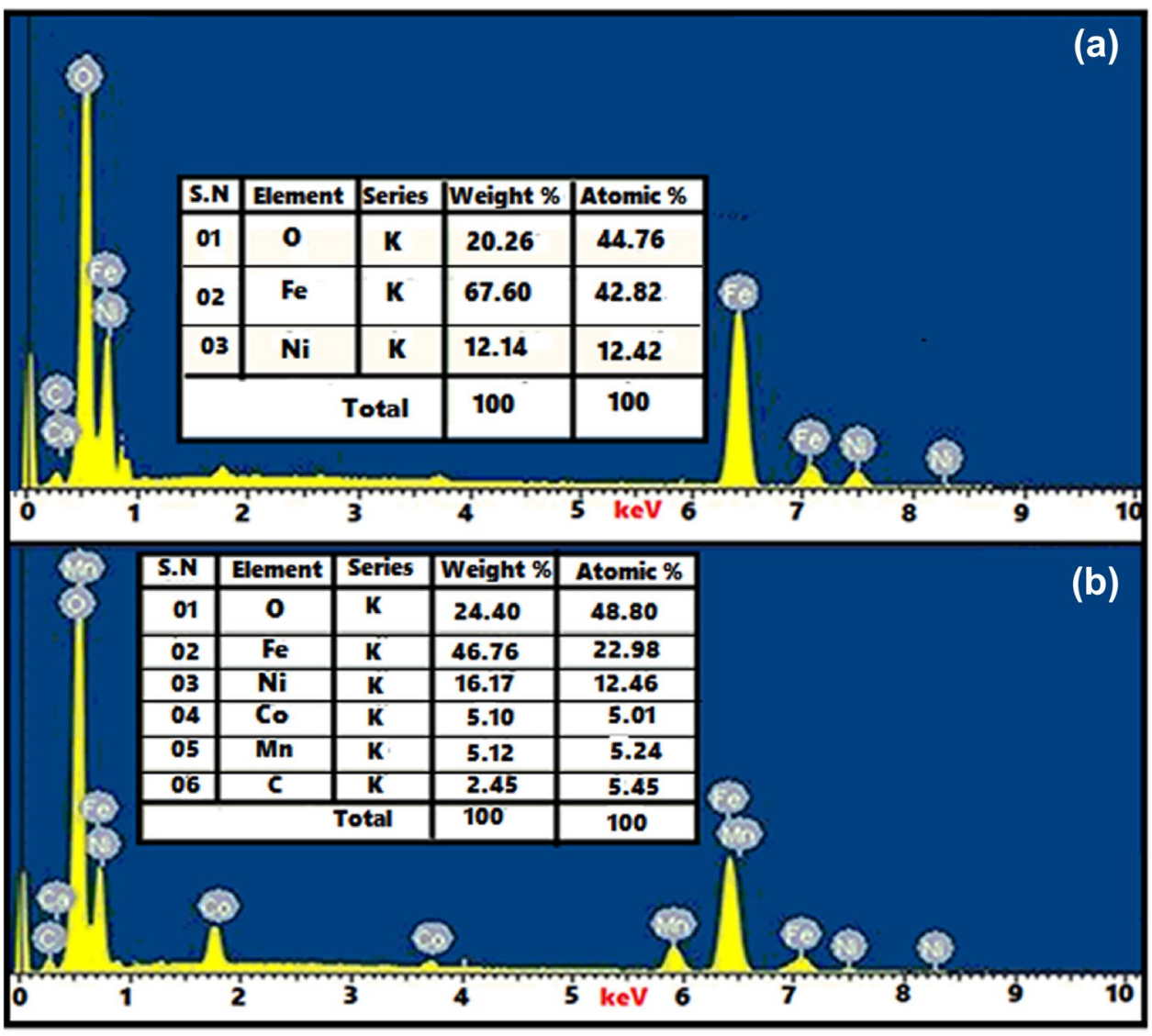

\section{FT-IR study}

Fourier-transform infrared analysis was performed for both pure and doped nickel ferrites (Fig. 6a) showing the FT-IR spectrum of pure $\mathrm{NiFe}_{2} \mathrm{O}_{4}$ thick films, whereas FT-IR spectrum of doped $\mathrm{NiF}_{2} \mathrm{O}_{4}$ is depicted in (Fig. 6b). Both spectra clearly show the various stretching and bending frequencies of functional material nickel ferrite in the inverse spinel arrangement as the $\mathrm{Ni}^{2+}$ and $\mathrm{Fe}^{3+}$ distributions are in different environments, i.e. octahedral and tetrahedral surrounding. The different stretching frequencies are attributed to this distribution which is found in the range of wave number $400-1000 \mathrm{~cm}^{-1}$. The two bands below $1000 \mathrm{~cm}^{-1}$ are considered to be highly characteristic frequencies for nickel ferrite. In Fig. 6a, the higher energy band $\left(\nu_{1}\right)$ in the frequency range of $609-650 \mathrm{~cm}^{-1}$ is assigned to tetrahedrally coordinated nickel oxygen stretching, while the lowest energy band $\left(\nu_{2}\right)$ is due to octahedrally co-ordinated metal oxygen vibration at $475.2 \mathrm{~cm}^{-1}$ [43]. The slightly curvy and broad bands observed in the spectrum are assigned to the absorbed and free water distributed in the crystal lattice of nickel ferrite as a water of crystallization observed at $3432.7 \mathrm{~cm}^{-1}$ and $1626.2 \mathrm{~cm}^{-1}$. In the case of inverse spinel nickel ferrite, some of the trivalent $\mathrm{Fe}^{3+}$ ions occupy tetrahedral voids. This typical stretch of $\mathrm{Fe}^{3+}$ and $\mathrm{O}^{2-}$ observed at $1027.4 \mathrm{~cm}^{-1}$ is governed to the migrated $\mathrm{Fe}^{3+}$ ions in tetrahedral voids [44]. In Fig. 6b, $\mathrm{Mn}^{2+}, \mathrm{Co}^{2+}$ doped nickel ferrite shows the characteristic wave number for all metal oxide vibrations. The typical $\mathrm{H}-\mathrm{O}-\mathrm{H}$ stretch for absorbed or free water is observed at $3321.3 \mathrm{~cm}^{-1}$ and $2340.2 \mathrm{~cm}^{-1}$. The water deformation peak is observed at $1433.4 \mathrm{~cm}^{-1}$ in doped nickel ferrite crystal lattice [45], while $1035.3 \mathrm{~cm}^{-1}$ wave number is assigned to trivalent iron atoms migrated in tetrahedral voids. The additional wave number at $600 \mathrm{~cm}^{-1}$ is assigned to doped cobalt oxide, while the band at $464.6 \mathrm{~cm}^{-1}$ is concerned with doped $\mathrm{Mn}^{2+}-\mathrm{O}^{2-}$ [46].

\section{Electrical properties}

The pure and doped nickel ferrites prepared by co-precipitation method, adhered on the glass substrate by utilizing screen printing, were analysed for electrical characterization and gas sensing measurements. The gas sensing performance was measured by home-made gas sensor assembly. Typically, the DC resistance of the thick films was measured by using half bridge method, in the atmosphere of different temperatures. The film was fixed at the base where chromel-alumel thermocouple was set to sense the temperature of the films sensor. The temperature sensed by thermocouple was digitally recorded by temperature 


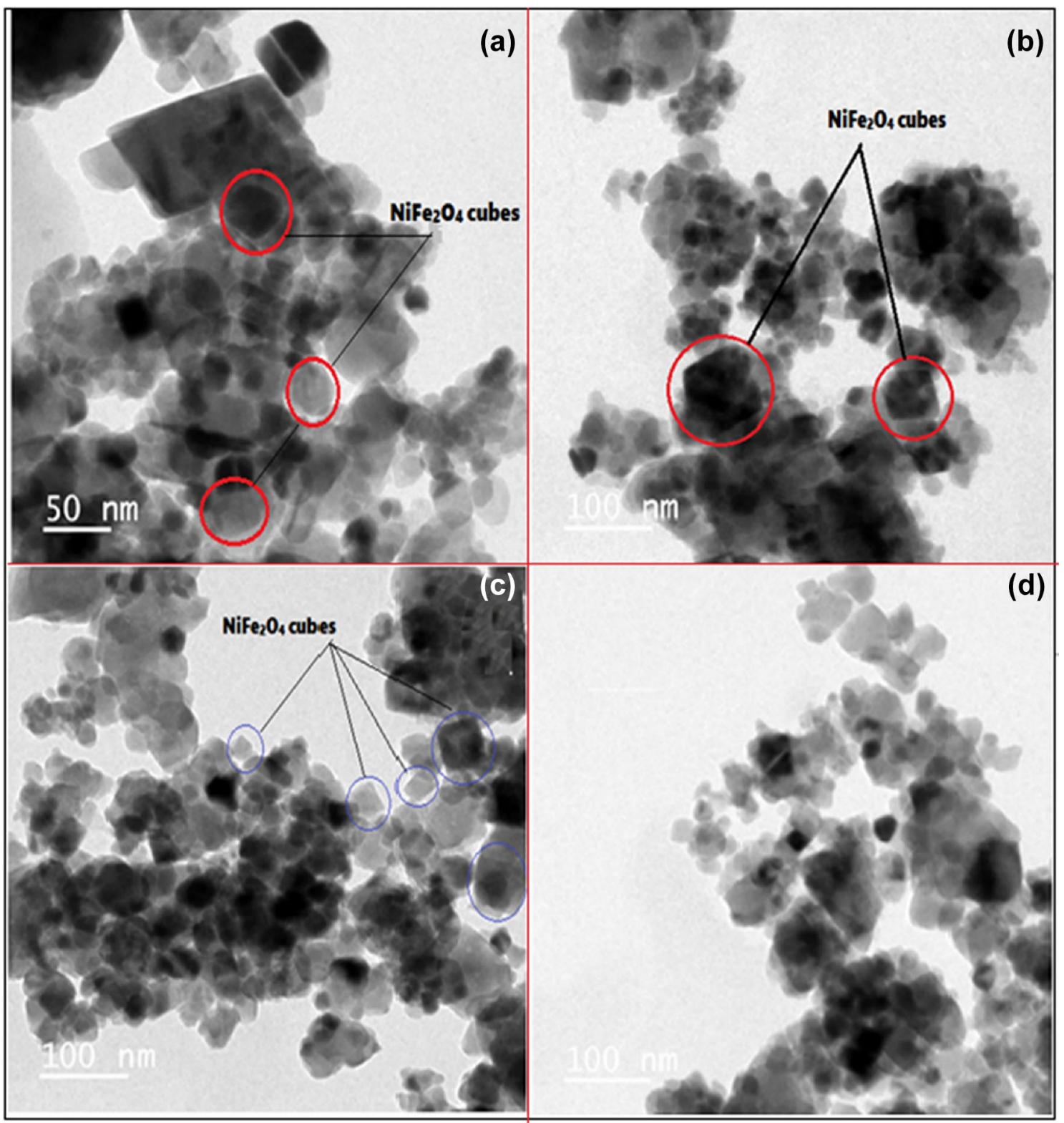

Fig. 4 a, b HR-TEM image of pure $\mathrm{NiFe}_{2} \mathrm{O}_{4}$ thick films. c, $\mathbf{d}$ HR-TEM image of $\mathrm{Mn}^{2+}$ and $\mathrm{Co}^{2+}$ doped $\mathrm{NiFe}_{2} \mathrm{O}_{4}$

recorder model number PEW-202/PEW-205. The gas concentration in ppm level is introduced inside the glass chamber sensing device at the base of apparatus via inlet pipe. The length of the pipe valve ends near the film sensor so that the contact between film sensor and gas should be maximum. The fixed DC voltage was applied to the circuit. The resistance of the films was measured by using output voltage digital multimeter model number CIE Classic 5175. At each cycle of gas introduced inside the glass chamber, gas residue was withdrawn by lifting the glass chamber and fixed temperature was supplied to remove the gas residue of the film. The oxygenated air was allowed to pass through the chamber at each gas sensitivity cycle.
The electrical resistance of the thick films in the presence of air $\left(R_{\mathrm{a}}\right)$, as well as in the presence of gas $\left(R_{\mathrm{g}}\right)$, was measured to calculate the gas response or sensitivity $(S)$ given by equation.

$S \%=R_{\mathrm{a}}-R_{\mathrm{g}} / R_{\mathrm{a}} \times 100$.

The sensitivity of the nickel ferrite thick film sensor was investigated on the gases such as LPG, $\mathrm{NO}_{2}, \mathrm{CH}_{3}-\mathrm{OH}$, $\mathrm{C}_{2} \mathrm{H}_{5}-\mathrm{OH}, \mathrm{NH}_{3}$ and petrol vapours at the optimum temperature of $50-350{ }^{\circ} \mathrm{C}$. The parts per million (ppm) concentrations of the selected gases were $500 \mathrm{ppm}$. The electrical resistance, selectivity, sensitivity, response recovery time were investigated for the thick film nickel ferrite sensors as 
Fig. 5 a Selected area electron diffraction (SAED) pattern of pure $\mathrm{NiFe}_{2} \mathrm{O}_{4}$, b SAED pattern of $\mathrm{Mn}^{2+}$ and $\mathrm{Co}^{2+}$ doped $\mathrm{NiFe}_{2} \mathrm{O}_{4}$
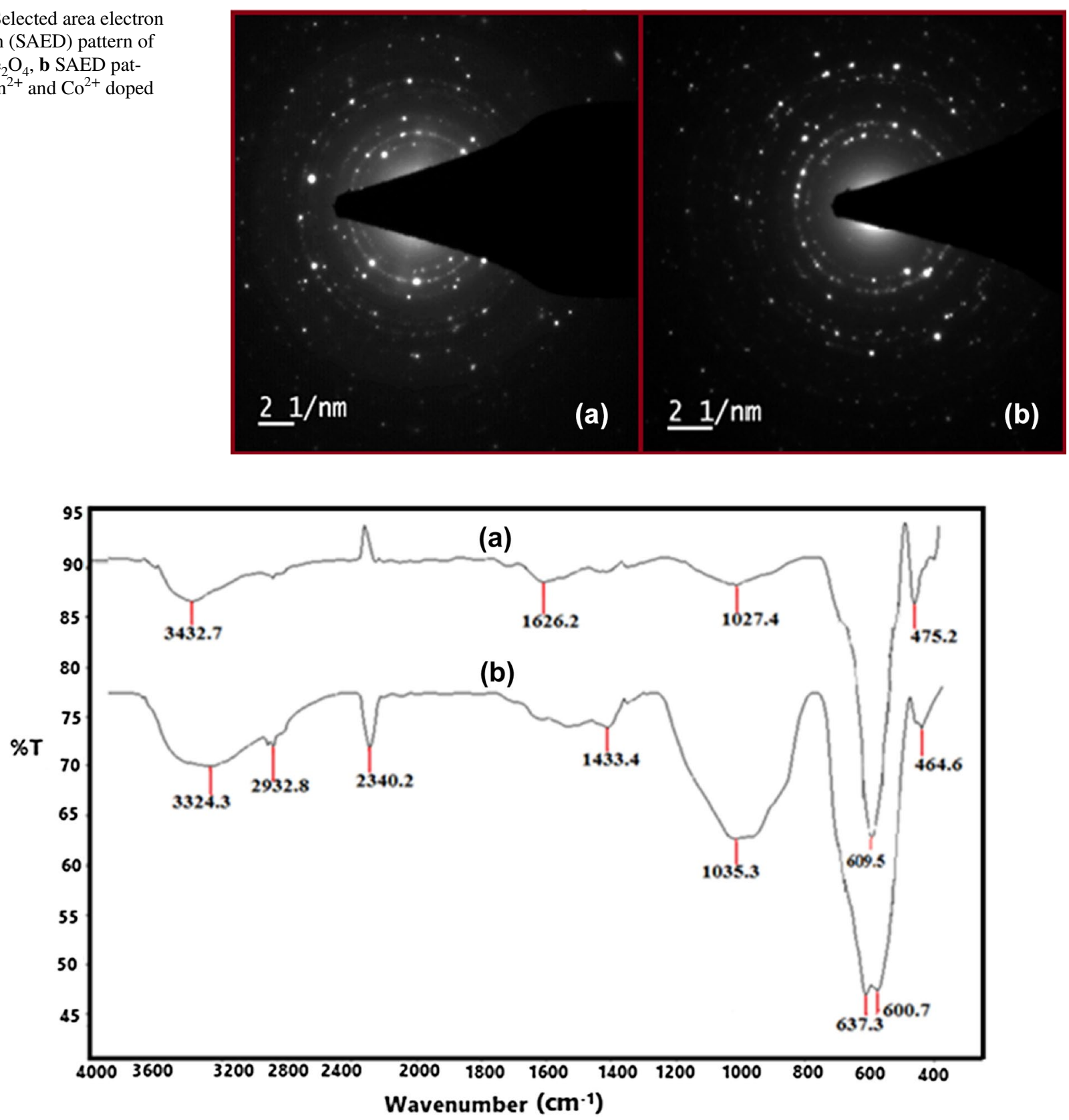

Fig. 6 a FT-IR spectrum of pure $\mathrm{NiFe}_{2} \mathrm{O}_{4}$ thick films. b FT-IR spectrum of $\mathrm{Mn}^{2+}$ and $\mathrm{Co}^{2+}$ doped $\mathrm{NiFe}_{2} \mathrm{O}_{4}$ thick films

well as for the modified ferrite sensors. The typical block diagram for gas sensing mechanism is shown in Fig. 7.

\section{Electrical resistivity and temperature effect on ferrite sensors}

The gas sensing properties of pure and modified nickel ferrite were investigated at different elevated temperatures from $350{ }^{\circ} \mathrm{C}$ to room temperature. The electrical resistance of the thick film sensor was measured in the presence of air without interpolation of any other gases in the glass-domed chamber with the regular set-up as depicted in Fig. 7. The typical semiconducting nature of pure and modified nickel ferrite is as shown in Fig. 8, where with a gradual decrease in temperature the change in resistance of the film was recorded. Resistance increases sharply at initial stage and step by step with a series of temperature resistance decreases. Figure $8 \mathrm{a}, \mathrm{c}$ shows lower resistance with increase in temperature because of increasing flow mobility of the charge moving or due to lattice vibrations associated with growing temperature, where the atoms often come closely sufficient for the transfer of the rate carriers and the conduction is initiated 


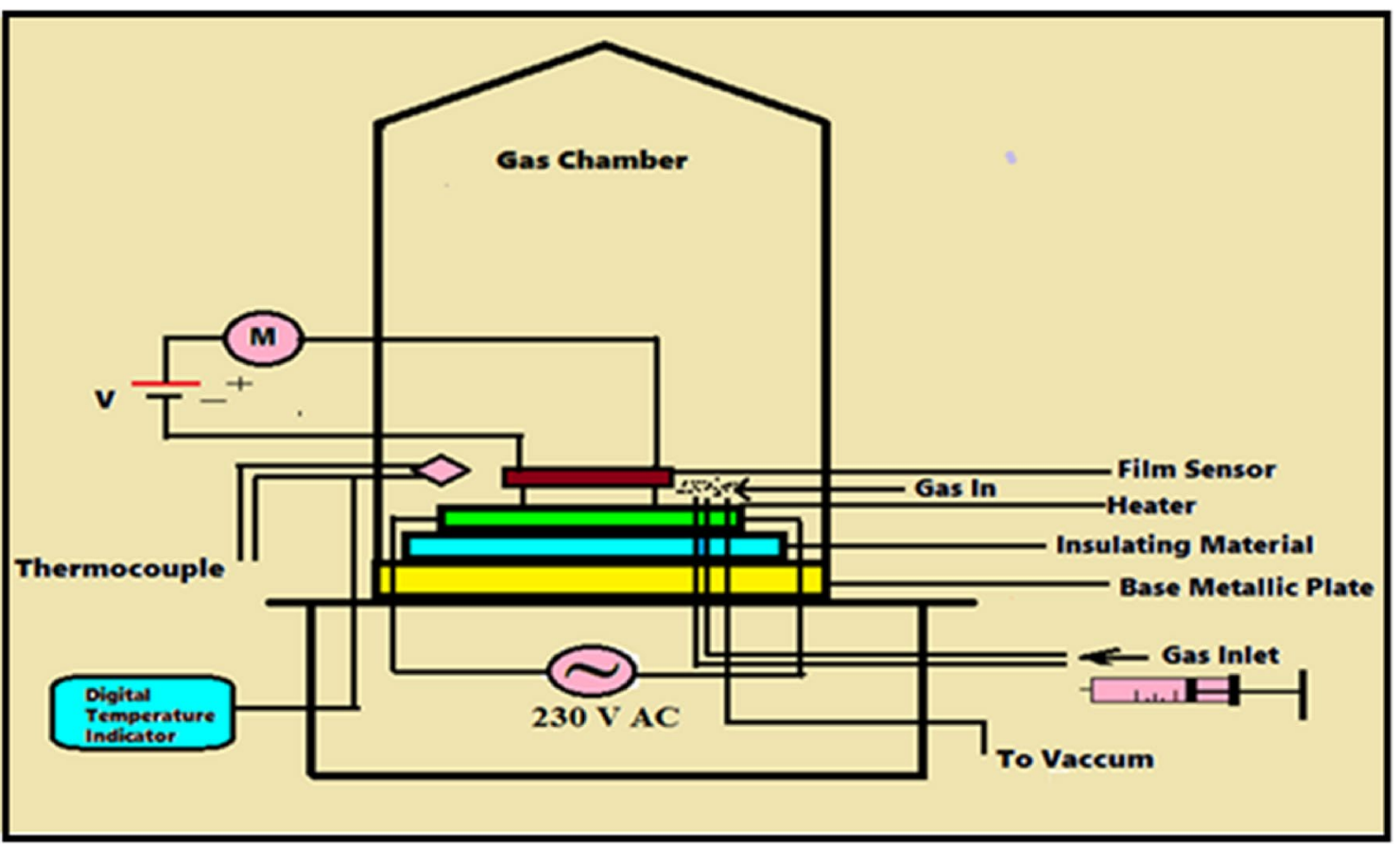

Fig. 7 Block diagram of a typical gas sensing apparatus

with the aid of lattice vibration $[47,48]$ (Table 2). Figure 8b, $\mathrm{d}$ shows the plot of $\log R$ against $1 / T$ form which the activation energy has been investigated for low- and high-temperature region. The resistivity of the pure and doped thick films was calculated by using Eq. (3).

$\rho=R \cdot b \cdot t / L$,

where $\rho$ is the resistivity of the film, $R$ is the resistance at room temperature, $b$ is the breadth of film, $t$ is the thickness of the film, $L$ is the length of the film.

The activation energy of pure and doped nickel ferrite material was calculated by using Eq. (4).

$R=R_{0} \mathrm{e}^{-\Delta E / K T}$,

$R$ is the resistance varied at different temperatures, $R_{0}$ is the resistance at $0{ }^{\circ} \mathrm{C}, \Delta E / T$ is the variation of energy with temperature, i.e. activation energy, $\Delta E=2.303 \times K \times$ slope (calculated from graph), $K$ is the Boltzmann constant $\left(8.61733 \times 10^{-5} \mathrm{eV} \mathrm{K}^{-1}\right)$.

\section{Sensitivity and selectivity of pure and modified nickel ferrites for the selected gases}

The sensitivity of various gases against temperature is shown in Figs. 9 and 10. The typical selectivity curves of pure and doped nickel ferrite are shown in Fig. 11a, b. The sensors of pure nickel ferrite and $\mathrm{Mn}^{2+}, \mathrm{Co}^{2+}$ doped nickel ferrite were tested for selected gases such as LPG, $\mathrm{NO}_{2}, \mathrm{CH}_{3}-\mathrm{OH}$, $\mathrm{C}_{2} \mathrm{H}_{5}-\mathrm{OH}, \mathrm{NH}_{3}$ and petrol vapours at the fixed concentration of $500 \mathrm{ppm}$. By supplying temperature to the sensor in the presence of particular gas, the sensitivity and selectivity can be calculated. Once the selectivity and sensitivity are calculated, one can conclude on the sensing ability of a material for the gas and construction of a sensor economically for the monitorization of the gases (Table 4). The gas sensing properties were strongly affected by the type of adsorption by the sensor surface. Depending on the type of adsorption, gas sensing adsorption may vary in metal oxide base semiconducting materials. The data collected from the selectivity of the gases indicate that pure nickel ferrite showed maximum selectivity for $\mathrm{NH}_{3}$ gas $100 \%$ at $50{ }^{\circ} \mathrm{C}$ followed by $\mathrm{NO}_{2}$ gas showed selectivity $95.86 \%$ at $250{ }^{\circ} \mathrm{C}$, for petrol vapours the selectivity is found be $79.76 \%$ and LPG selectivity by pure nickel ferrite was found to be $55.33 \%$. Most of the researchers worked on the nickel ferrite sensor for LPG and revealed that ferrites are excellent material as an LPG and $\mathrm{NH}_{3}$ sensors. But interestingly, the pure ferrite showed very good selectivity for $\mathrm{NO}_{2}$, which is very rarely reported. Further, the manganese- and cobalt-doped nickel ferrite showed some variation in the selectivity results probably due to effect of dopants. Here, the modified ferrite $\left(5 \% \mathrm{Mn}^{2+}, \mathrm{Co}^{2+}\right.$ doped nickel ferrite showed the highest selectivity for $\mathrm{NH}_{3}$, i.e. $100 \%$ at $150{ }^{\circ} \mathrm{C}$ for petrol vapours $94.02 \%$ at $100{ }^{\circ} \mathrm{C}$, selectivity of $\mathrm{NO}_{2}$ gas $93.96 \%$ at $100{ }^{\circ} \mathrm{C}$ and enhanced selectivity was observed $82.36 \%$ for LPG at $50{ }^{\circ} \mathrm{C}$, while methyl alcohol vapours showed $68.23 \%$ selectivity at $50{ }^{\circ} \mathrm{C}$. The comparative study for pure and modified gases and maximum response shown by the selected gases is listed in Table 3. 

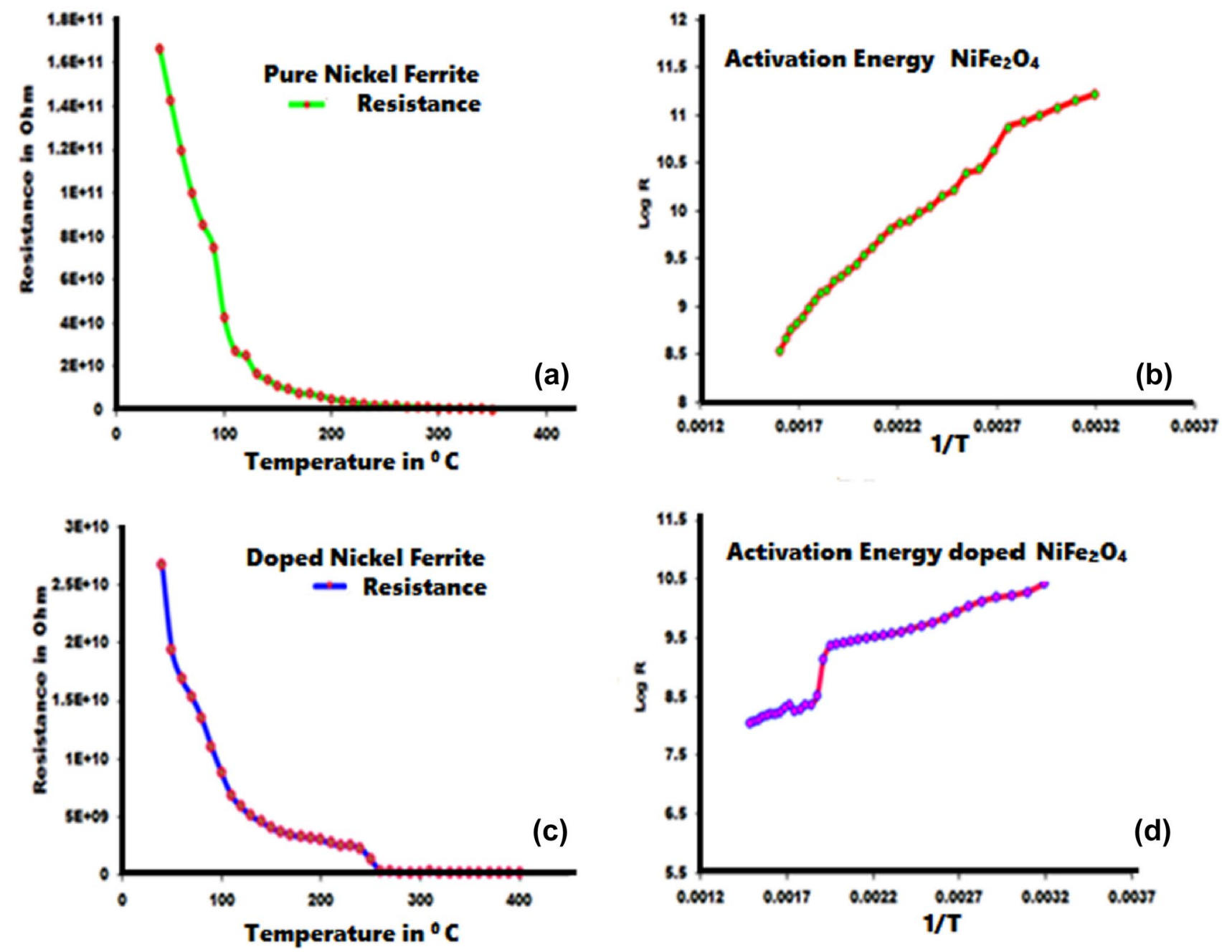

Fig. 8 a Variation of resistance with temperature for pure nickel ferrites. b Variation of resistance with temperature for doped nickel ferrites $750{ }^{\circ} \mathrm{C}$. c, $\mathbf{d}$ Plots of $\log R$ against $1 / T$ for activation energy of pure and doped nickel ferrite

Fig. 9 Plots of sensitivity verses temperature for pure nickel ferrite $(\mathrm{PNF})$ for various gases

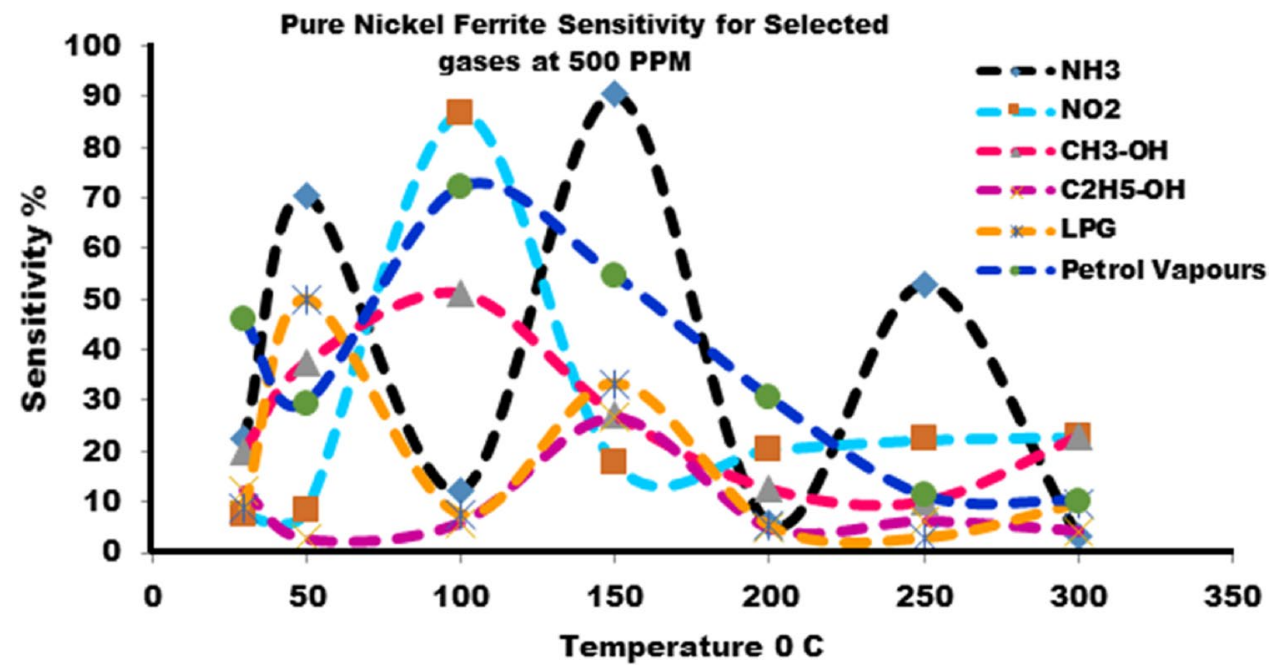


Fig. 10 Plot of sensitivity verses temperature for doped nickel ferrite (DNF) for various gases

Fig. 11 a Maximum selectivity of various gases for pure nickel ferrite sensors. b Selectivity of various gases for doped nickel ferrite sensors

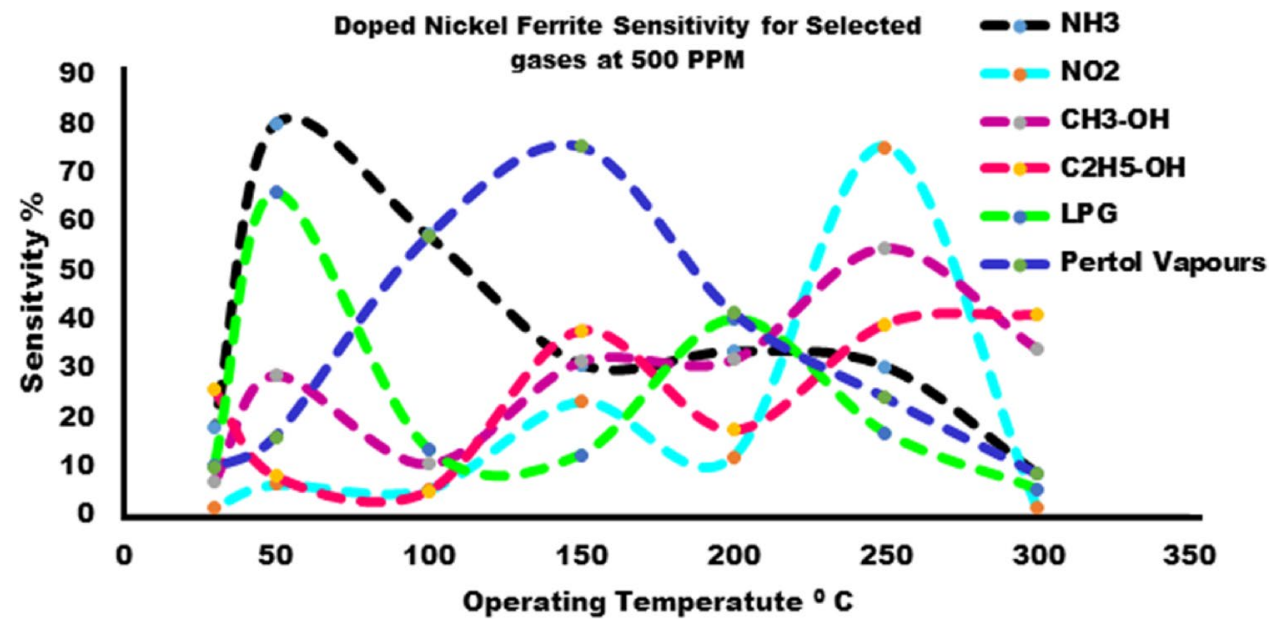

(a) Selectivity of gases for pure Ni-Ferrite

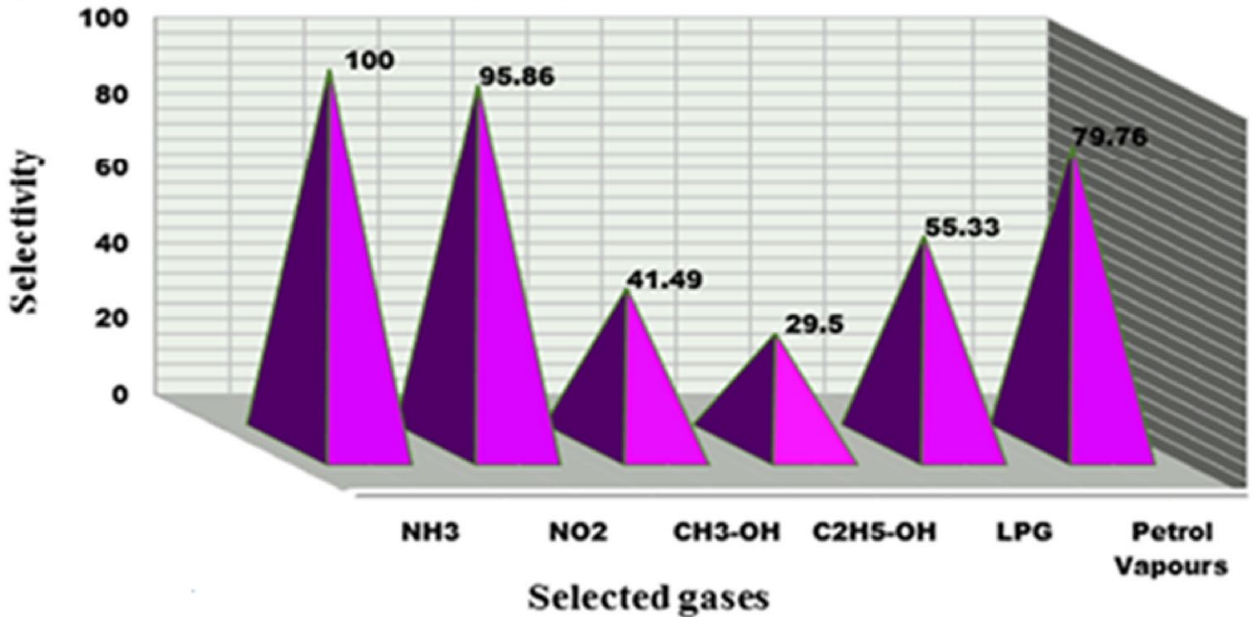

(b) Selectivity of Gases for Modified Ni-Ferrite

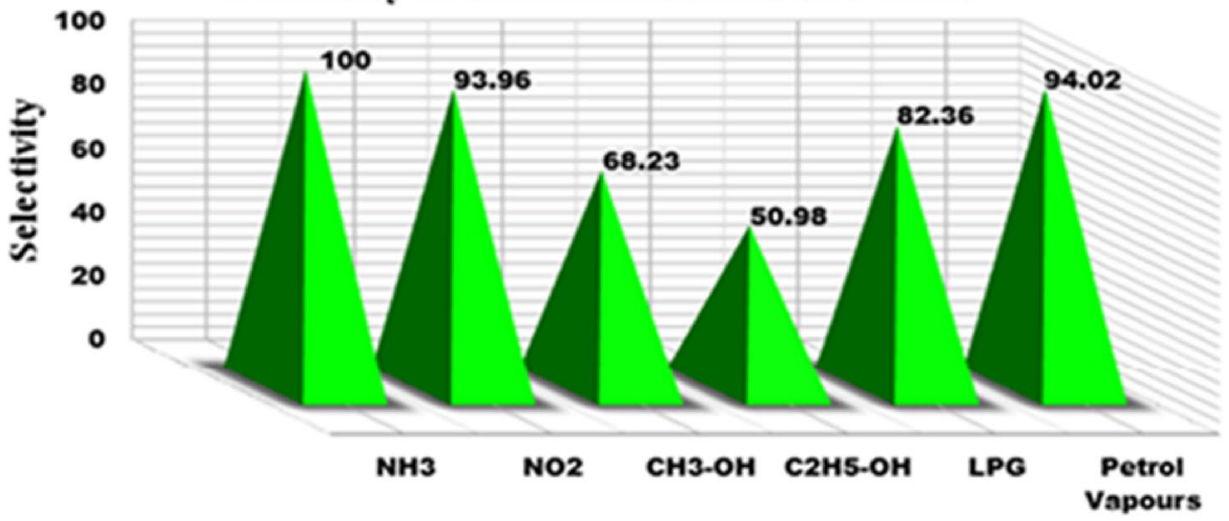

Selected Gases

\section{Response and ppm variation for pure and doped ferrite}

The maximum response for pure and modified nickel ferrite against the ppm variation is shown in Fig. 12a, b, where the percentage response and gas concentration in ppm were studied for ammonia, $\mathrm{NO}_{2}$ gas, petrol vapours. For both the materials, the response of the gases was found to be enhanced with elevation in gas concentration probably due to accumulation of more gas molecules on the surface of 
Table 2 Grain size, resistivity and activation energy for pure and doped nickel ferrites

\begin{tabular}{lllll}
\hline $\begin{array}{l}\text { Functional material } \\
\text { calcined at } 750{ }^{\circ} \mathrm{C}\end{array}$ & $\begin{array}{l}\text { Grain } \\
\text { size } \\
(\mathrm{nm})\end{array}$ & Resistivity $(\Omega \mathrm{m})$ & $\begin{array}{l}\text { Activation } \\
\text { energy }(\mathrm{eV})\end{array}$ \\
\cline { 4 - 5 } & & & LT & $\mathrm{HT}$ \\
\hline${\text { Pure } \mathrm{NiFe}_{2} \mathrm{O}_{4}}_{\text {Doped } \mathrm{NiFe}_{2} \mathrm{O}_{4}}^{23}$ & 28 & $5.368 \times 10^{3}$ & 0.20139 & 0.2299 \\
\hline
\end{tabular}

LT lower temperature, $H T$ high temperature

sensors. The typical adsorption of reacting gaseous molecules on sensor surface is responsible for incrementing the response of gases (Table 2).

\section{Response and recovery for pure and doped nickel ferrite}

Figure 13 represents the graphs for response and recovery of pure and doped nickel ferrite. The effectiveness of all the sensors depends on the important parameters such as response, recovery, stability and reproducibility, sensitivity of the base material sensor. All these properties are very effective for nickel ferrite as it contains good surface area, and hence, gas adsorption on its surface was found to be very effective due to physisorption and chemisorption phenomenon. The response and recovery time for pure and doped nickel ferrite were estimated, and the following observations were recorded and are shown in Table 4

\section{Conclusions}

1. Nanocrystalline inverse nickel ferrite and manganeseand cobalt-doped nickel ferrite ( $5 \%$ atomic weight) were prepared by a conventional co-precipitation method. The thick films of both pure and doped ferrites were prepared by screen printing method. The main aspects and important conclusions can be fetched from the all data and calculation of the present research according to the following summary.
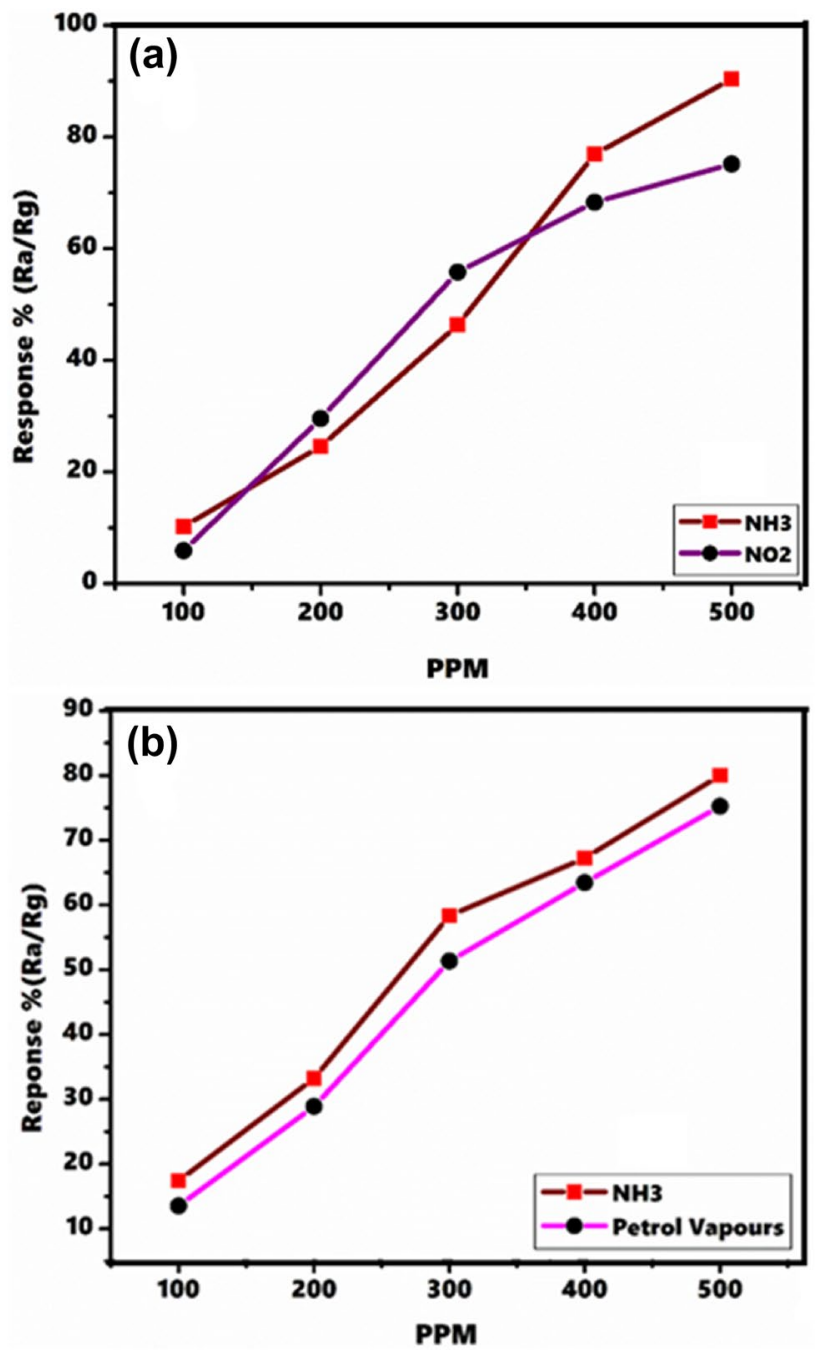

Fig. 12 a Maximum response for $\mathrm{NH}_{3}$ and $\mathrm{NO}_{2}$ gases with ppm variation for pure nickel ferrite. b Maximum response for $\mathrm{NH}_{3}$ and petrol vapours with $\mathrm{ppm}$ variation for doped nickel ferrites

2. The pure $\mathrm{NiFe}_{2} \mathrm{O}_{4}$ thick sensor was sensitive for $\mathrm{NH}_{3}$ up to 90.42 at $150{ }^{\circ} \mathrm{C}$, and for $\mathrm{NO}_{2}$ sensitivity was 86.68 at
Table 3 Summary for gas response in pure and modified nickel ferrite

\begin{tabular}{llllll}
\hline S. no. & Gases (500 ppm) & $\begin{array}{l}\text { \% response for pure } \\
\text { nickel ferrite (PNF) }\end{array}$ & $\begin{array}{l}\text { \% response for doped } \\
\text { nickel ferrite (DNF) }\end{array}$ & $\begin{array}{l}\text { Maximum } \\
\text { response }(T \\
\left.{ }^{\circ} \mathrm{C}\right)\end{array}$ & $\begin{array}{l}\text { Maximum } \\
\text { response }(T\end{array}$ \\
& & & $\begin{array}{l}\left.{ }^{\circ} \mathrm{C}\right) \\
\mathrm{DNF}\end{array}$ & $\mathrm{DN}$ \\
\hline 01 & $\mathrm{NH}_{3}$ & 90.42 & 80 & 50 & 150 \\
02 & $\mathrm{NO}_{2}$ & 86.68 & 75.17 & 250 & 100 \\
03 & $\mathrm{CH}_{3}-\mathrm{OH}$ & 37.52 & 54.59 & 300 & 50 \\
04 & $\mathrm{C}_{2} \mathrm{H}_{5}-\mathrm{OH}$ & 26.28 & 40.79 & 50 & 50 \\
05 & $\mathrm{LPG}$ & 50.03 & 65.89 & 150 & 100 \\
06 & Petrol vapours & 72.12 & 75.25 & & 50 \\
\hline
\end{tabular}



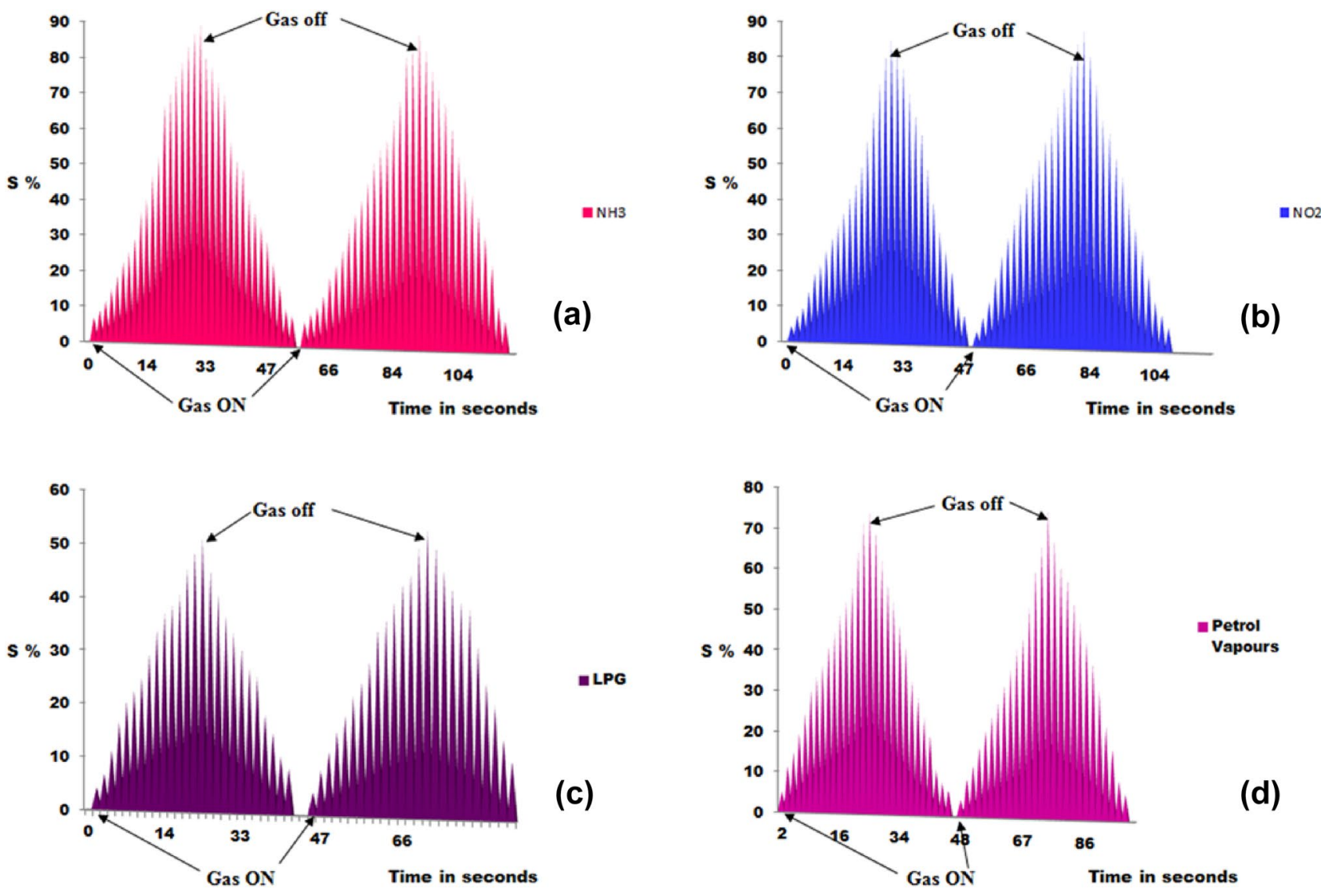

Fig. 13 Response and recovery graph $\mathbf{a}$ for ammonia and $\mathbf{b}$ for $\mathrm{NO}_{2}$ gas in pure nickel ferrite. Response and recovery graph $\mathbf{c}$ for LPG and $\mathbf{d}$ for petrol vapours gas in doped nickel ferrite

Table 4 Summary of response and recovery for pure and doped nickel ferrite

\begin{tabular}{lllll}
\hline Figure code & Name of gas & $\begin{array}{l}\text { Maximum } \\
\text { response (\%) }\end{array}$ & $\begin{array}{l}\text { Response } \\
\text { time in s }\end{array}$ & $\begin{array}{l}\text { Recovery } \\
\text { time in s }\end{array}$ \\
\hline $\mathrm{A}$ & $\mathrm{NH}_{3}$ & 90.42 & 32 & 22 \\
$\mathrm{~B}$ & $\mathrm{NO}_{2}$ & 86.68 & 30 & 17 \\
$\mathrm{C}$ & $\mathrm{LPG}$ & 65.89 & 24 & 19 \\
$\mathrm{D}$ & Petrol vapours & 75.25 & 26 & 22 \\
\hline
\end{tabular}

$100{ }^{\circ} \mathrm{C}$.

3. In most of the gas sensing study, pure nickel ferrite showed good response for LPG vapours. In the present research, we interpreted the results and found that pure as well as doped nickel ferrite was sensitive for LPG gas. Maximum response shown by pure nickel ferrite for LPG was found to be 50.03 at $50{ }^{\circ} \mathrm{C}$, and enhanced response was observed for doped nickel ferrite 65.89 at $50{ }^{\circ} \mathrm{C}$.
4. For doped nickel ferrite, maximum response shown by $\mathrm{NH}_{3}$ and petrol vapours was found to be 80.0 and 75.25 at $150{ }^{\circ} \mathrm{C}$ and $100{ }^{\circ} \mathrm{C}$, respectively.

5. The effect of dopant concentration has been investigated to visualize any change in response of gas due to dopant addition to the base material nickel ferrite. In the observations, it is found that doped nickel ferrite is very sensitive to petrol vapours as well as to ammonia and LPG.

6. The ppm variation for pure $\mathrm{NiFe}_{2} \mathrm{O}_{4}$ for $\mathrm{NH}_{3}, \mathrm{NO}_{2}$ was investigated from 100 to $500 \mathrm{ppm}$, and a steady increased response was observed for increase in concentration of gases.

7. The gas sensing procedure for selected gases with usual mechanism was set up successfully for prepared sensors.

8. Response and recovery time were found to be very effective for ammonia, $\mathrm{NO}_{2}$, LPG and petrol vapours as mentioned in Fig. 13.

Acknowledgements Authors gratefully acknowledge the SAIF UDCT, Jalgaon (M.S.), for XRD and SEM analysis. Authors are thankful to SAIF IIT Bombay for TEM and EDX analysis as well as SAIF 
Chandigarh (Punjab University) for FT-IR study. Authors are very thankful to Department of chemistry, Pratap College, Amalner, Department of Chemistry, L.V.H. College, Panchavati, Nashik, and Department of Electronics L.V.H. College, Panchavati, Nashik, for providing necessary laboratory facilities.

Open Access This article is distributed under the terms of the Creative Commons Attribution 4.0 International License (http://creativeco mmons.org/licenses/by/4.0/), which permits unrestricted use, distribution, and reproduction in any medium, provided you give appropriate credit to the original author(s) and the source, provide a link to the Creative Commons license, and indicate if changes were made.

\section{References}

1. Kamble, R.B., Mathe, V.L.: Nanocrystalline nickel ferrite thick film as an efficient gas sensor at room temperature. Sens. Actuators, B 131, 205-209 (2008)

2. Dixit, G., Singh, J.P., Srivastava, R.C., Agrawal, H.M., Choudhary, R.J., Gupta, A.: Annealing effect on the structural and magnetic properties of nickel ferrite thin films. Surf. Interface Anal. 42, 151-156 (2010)

3. Rezlescu, E., Iftimie, N., Popa, P.D., Rezlescu, N.: Porous nickel ferrite for semiconducting gas sensor. J. Phys: Conf. Ser. 15, 51-54 (2005)

4. Baruwati, B., Reddy, K.M., Manoramaa, S.V.: Tailored conductivity behavior in nanocrystalline nickel ferrite. Appl. Phys. Lett. 85(14), 2833-2835 (2004)

5. Kumar, Y., Sharma, A., Shirage, P.M.: Shape-controlled $\mathrm{CoFe}_{2} \mathrm{O}_{4}$ nanoparticles as an excellent material for humidity sensing. RSC Adv. 7(88), 55778-55785 (2017)

6. Moghaddama, M.F., Tavakolia, G., Aliabadia, A.: Application of nickel ferrite and cobalt ferrite magnetic nanoparticles in $\mathrm{C}-\mathrm{O}$ bond formation: a comparative study between their catalytic activities. RSC Adv. 5(73), 59142-59153 (2015)

7. Sharma, P., Sharma, A., Sharma, M., Bhalla, N., Estrela, P., Jain, A., Thakur, P., Thakur, A.: Nanomaterial fungicides: in vitro and in vivo antimycotic activity of cobalt and nickel nanoferrites on phytopathogenic fungi. Global Chall 1, 1700041 (2017)

8. Patil, M.R., Shrivastava, V.S.: Adsorptive removal of methylene blue from aqueous solution by polyaniline-nickel ferrite nanocomposite: a kinetic approach. Desalin. Water Treat. 57(13), 5879-5887 (2016)

9. Sun, C., Lee, J.S.H., Zhang, M.: Magnetic nanoparticles in MR imaging and drug delivery. Adv. Drug Deliv. Rev. 60, 12521265 (2008)

10. Shan, J., Bougiatioti, P., Liang, L., Reiss, G., Kuschel, T., van Wees, B.J.: Nonlocal magnon spin transport in $\mathrm{NiFe}_{2} \mathrm{O}_{4}$ thin films. Appl. Phys. Lett. 110(13), 132406 (1-5) (2017)

11. Singh, A., Singh, R., Singh, S., Tandon Yadav, B.C.: Preparation and characterization of nanocrystalline nickel ferrite thin films for development of a gas sensor at room temperature. J. Mater. Sci.: Mater. Electron. 27(8), 8047-8054 (2016)

12. Koli, P.B., Kapadnis, K.H., Deshpande, U.G.: Methanol gas sensing properties of pervoskite $\mathrm{LaFeO}_{3}$ nanoparticles doped by transition metals $\mathrm{Cr}^{3+}$ and $\mathrm{Co}^{2+}$. J. Chem. Pharm. Res 9(1), 253-259 (2017)

13. Rong, Q., Zhang, Y., Wang, C., Zhu, Z., Zhang, J., Liu, Q.: A high selective methanol gas sensor based on molecular imprinted $\mathrm{Ag}-\mathrm{LaFeO}$ fibers. Sci. Rep. 7, 12110 (2017)

14. Siemons, M., Leifert, A., Simon, U.: Preparation and gas sensing characteristics of nanoparticulate p-type semiconducting
$\mathrm{LnFeO}_{3}$ and $\mathrm{LnCrO}_{3}$ materials. Adv. Funct. Mater. 17, 2189 2197 (2007)

15. Hajihashemi, R., Rashidi, A.M., Alaie, M., Mohammadzadeh, R., Izadi, N.: The study of structural properties of carbon nanotubes decorated with $\mathrm{NiFe}_{2} \mathrm{O}_{4}$ nanoparticles and application of nanocomposite thin film as $\mathrm{H}_{2} \mathrm{~S}$ gas sensor. Mater. Sci. Eng., C 44, 417-421 (2014)

16. Syepelak, V., Bergmann, I., Feldhoff, A., Heitjans, P., Krumeich, F., Menzel, D., Litterst, F.J., Campbell, S.J., Becker, K.D.: Nanocrystalline nickel ferrite, $\mathrm{NiFe}_{2} \mathrm{O}_{4}$ : mechanosynthesis, nonequilibrium cation distribution, canted spin arrangement, and magnetic behavior. J. Phys. Chem. C 111, 5026-5033 (2007)

17. Chavan, P., Naik, L.R.: Investigation of energy band gap and Conduction mechanism of magnesium substituted nickel ferrite nanoparticles. Phys. Status Solid A 214(9), 1-8 (2017)

18. Koseoglu, Y., Bay, M., Tan, M., Baykal, A., Sozeri, H., Topkaya, R., Akdogan, N.: Magnetic and dielectric properties of nanoparticles synthesized by PEG-assisted hydrothermal method. J Nanoparticle Res 13, 2235-2244 (2011)

19. Perron, H., Mellier, T., Domain, C., Roques, J., Simoni, E., Drot, R., Catalette, H.: Structural investigation and electronic properties of the nickel ferrite $\mathrm{NiFe}_{2} \mathrm{O}_{4}$ : a periodic density functional theory approach. J. Phys.: Condens. Matter 19, 346219 (2017)

20. Sivakumar, P., Ramesh, R., Ramanand, A., Ponnusamy, S., Muthamizhchelvan, C.: Synthesis and characterization of nickel ferrite magnetic nanoparticles. Mater. Res. Bull. 46, 2208-2211 (2011)

21. Parishani, M., Nadafan, M., Dehghani, Z., Malekfar, R., Khorrami, G.H.: Optical and dielectric properties of $\mathrm{NiFe}_{2} \mathrm{O}_{4}$ nanoparticles under different synthesized temperature. Results Phys 7, 3619-3623 (2017)

22. Srivastava, M., Chaubey, S., Ojha, A.K.: Investigation on size dependent structural and magnetic behavior of nickel ferrite nanoparticles prepared by sol-gel and hydrothermal methods. Mater. Chem. Phys. 118, 174-180 (2009)

23. Dong, C., Wang, G., Guo, D., Jiangand, C., Xue, D.: Growth, structure, morphology, and magnetic properties of Ni ferrite films. Nanoscale Res. Lett. 8(1), 196 (2013)

24. Hong, D., Yamada, Y., Sheehan, M., Shikano, S., Kuo, C., Tian, M., Tsung, C., Fukuzumi, S.: Mesoporous nickel ferrites with spinel structure prepared by an aerosol spray pyrolysis method for photocatalytic hydrogen evolution. ACS Sustain. Chem. Eng 2, 2588-2594 (2014)

25. Srivastava, R., Yadav, B.C., Singh, M., Yadav, T.P.: Synthesis, characterization of nickel ferrite and its uses as humidity and LPG sensor. Inorg. Organomet. Polym. 26(6), 1404-1412 (2016)

26. Dumitrescu, A.M., Lisa, G., Iordan, A.R., Tudorache, F., Petrila, I., Borhan, A.I., Palamaru, M.N., Mihailescu, C., Leontie, L., Munteanu, C.: Ni ferrite highly organized as humidity sensors. Mater. Chem. Phys. 156, 170-179 (2015)

27. Darshane, S.L., Suryavanshi, S.S., Mulla, I.S.: Nanostructured nickel ferrite: a liquid petroleum gas sensor. Ceram. Int. 35, 1793-1797 (2009)

28. Patil, A.V., Dighavkar, C.G., Sonawane, G.K., Patil, S.J., Borse, R.Y.: Formulation and characterization of $\mathrm{Cr}_{2} \mathrm{O}_{3}$ doped $\mathrm{ZnO}$ thick films as $\mathrm{H}_{2} \mathrm{~S}$ gas sensor. Sens. Transducers J 108(9), 189197 (2009)

29. Sivakumar, P., Ramesh, R., Ramanand, A., Ponnusamy, S., Muthamizhchelvan, C.: Synthesis and characterization of $\mathrm{NiFe}_{2} \mathrm{O}_{4}$ nanoparticles and nanorods. J. Alloys Compd. 563, 6-11 (2013)

30. Rajput, A.B., Hazra, S., Krishna, N.B., Chavali, P., Datla, S., Ghosh, N.N.: Preparation of $\mathrm{NiFe}_{2} \mathrm{O}_{4}$ nanopowder via EDTA precursor and study of its properties. Particuology 10, 29-34 (2012) 
31. Rao, P., Godbole, R.V., Bhagwat, S.: Nanocrystalline Pd: $\mathrm{NiFe}_{2} \mathrm{O}_{4}$ thin films: a selective ethanol gas sensor. J. Magn. Magn. Mater. 416, 292-298 (2016)

32. Gabal, M.A., Kosa, S., Muttairi, T.S.E.: Magnetic dilution effect of nano-crystalline $\mathrm{NiFe}_{2} \mathrm{O}_{4}$ synthesized via sucrose-assisted combustion route. Ceram. Int. 40, 675-681 (2014)

33. Xu, Y., Sun, D., Hao, H., Gao, D., Sun, Y.: Non-stoichiometric $\mathrm{Co}$ (II), Ni(II), Zn(II)-ferrite nanospheres: size controllable synthesis, excellent gas-sensing and magnetic properties. RSC Adv. 6, 98994-99002 (2016)

34. Mondal, S., Kumari, M., Madhuri, R., Sharma, P.K.: Acetaminophen and acetone sensing capabilities of nickel ferrite nanostructures. Appl. Phys. A 123(494), 1-15 (2017)

35. Benrabaa, R., Boukhlouf, H., Lofberg, A., Rubbens, A., Vannier, R., Richard, E.B., Barama, A.: Nickel ferrite spinel as catalyst precursor in the dry reforming of methane: synthesis, characterization and catalytic properties. J. Nat. Gas Chem. 21, 595-604 (2012)

36. Dar, M.A., Shah, J., Siddiqui, W.A., Kotnala, R.K.: Study of structure and magnetic properties of $\mathrm{Ni}-\mathrm{Zn}$ ferrite nano-particles synthesized via co-precipitation and reverse micro-emulsion technique. Appl. Nanosci. 4, 675-682 (2014)

37. Abbas, Z., Holmberg, J.P., Hellstrom, A.K., Hagstrom, M., Bergenholtz, J., Hassellov, M., Ahlberg, E.: Synthesis, characterization and particle size distribution of $\mathrm{TiO}_{2}$ colloidal nanoparticles. Colloids Surf. A Physicochem. Eng. Aspects 384, 254-261 (2011)

38. Ishaq, K., Saka, A.A., Kamardeen, A.O., Ahmed, A., Alhassan, M.I., Abdullahi, H.: Characterization and antibacterial activity of nickel ferrite doped alumina nanoparticle. Eng. Sci. Technol. Int. J. 20, 563-569 (2017)

39. Sozeri, H., Zehra, D., Baykal, A.: Structural and magnetic properties of triethylene glycol stabilized $\mathrm{Zn}_{x} \mathrm{Co}_{1-x} \mathrm{Fe}_{2} \mathrm{O}_{4}$ nanoparticles. Mater. Res. Bull. 47(9), 2442-2448 (2012)

40. Pubby, K., Narang, S.B.: Influence of grain size and porosity on $\mathrm{X}$-band properties of $\mathrm{Mn}-\mathrm{Zr}$ substituted $\mathrm{Ni}-\mathrm{Co}$ ferrites. Mater. Lett. 244, 186-191 (2019)

41. Klekotk, U., Rogowska, M., Satuła, D., Szostko, B.: Characterization of ferrite nanoparticles for preparation of biocomposites. Beilstein J. Nanotechnol. 8, 1257-1265 (2017)
42. Senthilkumar, B., Selvan, R.K., Vinothbabu, P., Perelshtein, I., Gedanken, A.: Structural, magnetic, electrical and electrochemical properties of $\mathrm{NiFe}_{2} \mathrm{O}_{4}$ synthesized by the molten salt technique. Mater. Chem. Phys. 130, 285-292 (2011)

43. Khan, A.A., Javed, M., Khan, A.R., Iqbal, Y., Majeed, A., Hussain, S.Z., Durrani, S.K.: Influence of preparation method on structural, optical and magnetic properties of nickel ferrite nanoparticles. Mater. Sci. Pol. 35(1), 58-65 (2017)

44. Shanmugavel, T., Raj, S.G., Kumar, G.R., Rajarajan, G., Saravanan, D.: Cost effective preparation and characterization of nanocrystalline nickel ferrites $\left(\mathrm{NiFe}_{2} \mathrm{O}_{4}\right)$ in low temperature regime. J King Saud Univ. Sci. 27, 176-181 (2015)

45. Babadi, N., Tavakkoli, H., Afshari, M.: Synthesis and characterization of nanocomposite $\mathrm{NiFe}_{2} \mathrm{O}_{4} @$ SalenSi and its application in efficient removal of $\mathrm{Ni}$ (II) from aqueous solution. Bull. Chem. Soc. Ethiop. 32(1), 77-88 (2018)

46. Patil, A.V., Dighavkar, C.G., Sonawane, G.K., Patil, S.J., Borse, R.Y.: Effect of firing temperature on electrical and structural characteristics of screen printed $\mathrm{TiO}_{2}$ thick films. Optoelectron. Adv. Mater. 3(10), 1013-1017 (2009)

47. Bharathi, K.K., Alam, M., Vemuri, R.S., Ramana, C.V.: Correlation between microstructure, electrical and optical properties of nanocrystalline $\mathrm{NiFe}_{1.925} \mathrm{Dy}_{0.075} \mathrm{O}_{4}$ thin films. RSC Adv. 2, 941-948 (2012)

48. Pubby, K., Meena, S.S., Yusuf, S.M., Narang, S.B.: Cobalt substituted nickel ferrites via Pechini's sol-gel citrate route: X-band electromagnetic characterization. J. Magn. Magn. Mater. 466, 430-445 (2018)

Publisher's Note Springer Nature remains neutral with regard to jurisdictional claims in published maps and institutional affiliations. 